\title{
Therapeutic and prophylactic effects of a protective monoclonal antibody (MAb-001) against the pathogenic haemoflagellate Cryptobia salmositic
}

\author{
Shujuan Feng, Patrick T. K. Woo* \\ Department of Zoology, University of Guelph, Guelph, Ontario, Canada N1G 2W1
}

\begin{abstract}
We recently produced a species-specific monoclonal antibody (MAb-001) against a surface antigen of Cryptobia salmositica Katz 1951 When a single dose (4\% body of weight in ml) of MAb001 was injected into fish infected with $C$. salmositica, subsequent parasitaemias were significantly $(p<0.05)$ reduced at $48 \mathrm{~h}$ after treatment. Parasitaemias were still significantly lower than in control fish (injected with cold-blooded vertebrate Ringer's solution, CBVR) 1 wk after injection of MAb-001. There was no significant difference in parasitaemias between injection of a single dose or a double dose of MAb-001. Injection of MAb-001 into fish before infection and at $1 \mathrm{wk}$ after infection did not prevent infection. Parasitaemias in fish which received MAb on Days $0,1,2,3,4,5,6$ (daily injected fish) were significantly higher than in fish which received CBVR. The production of complement-fixing antibody against $C$. salmositica in MAb daily injected fish was significantly lower than in those injected with CBVR. Antibodies against MAb-001 were detected in fish injected daily with MAb-001 These results suggest that a single dose of MAb-001 is therapeutic and perhaps can be used to prevent mortality of infected fish. Injection of MAb-001 every day in the first week after infection induced significant antigenic competition between parasites and MAb-001 Consequently, these fish produced less complement-fixing antibody against $C$. salmositica and this resulted in higher parasitaemias than in CBVR-injected fish.
\end{abstract}

KEY WORDS: Cryptobia salmositica - Haemoflagellate Immunotherapy - Monoclonal antibody Protection

\section{INTRODUCTION}

Cryptobia salmositica Katz 1951 is a pathogenic haemoflagellate in salmonids on the west coast of North America and natural infections have been reported in all species of Pacific salmon (Woo 1987, 1994). Rainbow trout Oncorhynchus mykiss are susceptible to infection and develop clinical disease with exophthalmia, abdominal distension with ascites, splenomegaly, anemia and anorexia (Woo 1979, Thomas \& Woo 1992). Considerable efforts have been directed to understand the protective mechanism in fish against this parasite. In vitro and in vivo cell mediated immune responses $\left(\mathrm{T}_{\mathrm{DTH}}\right.$ reaction, phagocytosis, $\mathrm{MMI}$ ) have

\footnotetext{
·Addressee for correspondence. E-mail: pwoo@uoguelph.ca
}

been demonstrated in experimentally infected rainbow trout (Thomas \& Woo 1990, Li \& Woo 1995, Feng \& Woo 1996). Both agglutinating and complement-fixing antibodies were detected in infected and vaccinated rainbow trout (Jones \& Woo 1987, Woo \& Li 1990, SitjaBobadilla \& Woo 1994, Li \& Woo 1995, Feng \& Woo $1996)$, and an in vitro assay has been used to evaluate the importance of antibodies in protective immunity against $C$. salmositica. Passive transfer of antibodies against $C$. salmositica from immune fish to nonimmune fish showed partial protection (Jones \& Woo 1987). In a recent study, we (Feng \& Woo 1996) produced a species-specific monoclonal antibody against a surface antigen on $C$. salmositica. This antibody is cytotoxic to C. salmositica under in vitro conditions.

Monoclonal antibodies with in vitro cytotoxity have been produced against mammalian protozoans, i.e. 
Plasmodium knowlesi, P. falciparum, P. chabaudi, Trypanosoma brucei rhodesiense, $T$. cruzi, Giardia lamblia, and G. muris (see Epstein et al. 1981, Boyle et al. 1982, Saul et al. 1984, Pinder et al. 1987, Araguth et al. 1988, Bustcher et al. 1988, Campbell \& Faubert 1994), and against a fish parasite, Ichthyophthirius multifiliis (see Lin et al. 1994). However, only a few of them are known to be protective in the host. Monoclonal antibodies against the rodent malaria parasites $P$. chabaudi and $P$. yoelii delayed and decreased parasitaemias when they were injected into infected animals (Freeman et al. 1980, Boyle et al. 1982). A strain-specific $\mathrm{MAb}$ against $G$. lamblia is cytotoxic under in vitro conditions and MAbs against $G$. muris are therapeutic (Nash \& Aggarwal 1986, Butscher \& Faubert 1988). Monoclonal antibody against $I$. multifiliis protected fish from infection when it was injected intraperitoneally into channel catfish (Lin et al. 1994).

The aims of the present study were to examine the therapeutic and prophylactic effects of MAb-001 on acute Cryptobia salmositica infection in rainbow trout.

\section{MATERIAL AND METHODS}

Source and maintenance of fish. A total of 160 disease-free juvenile rainbow trout Oncoryhnchus mykiss purchased from a local hatchery (Wildcat Trout Farm, Thamesford, Ontario, Canada) were used in the study. The fish (weight approximately 10 to $15 \mathrm{~g}$ and 10 to $15 \mathrm{~cm}$ in length) were maintained in plastic circular tanks (128 l) with constant aeration and flowing well water. The water temperature varied between 6.5 and $13^{\circ} \mathrm{C}$ during the year. Fish were held under a $12 \mathrm{~h}$ light:12 h dark photoperiod, and were fed daily to satiety with commercial trout diet (Martin's Feed Mills, Elmira, Ontario).

Branding and bleeding. Fish were anaesthetized in a $200 \mathrm{ppm}$ solution of tricaine methanesulfonate (MS222) (Finquel Brand, Argent Chemical Laboratories, Redmond, WA 98052, USA) before branding or bleeding. The caudal and anal fins of some fish were branded using a $15 \mathrm{~A}$ wood-burning iron according to the method of McNical \& Noakes (1979) to provide individual identification.

A disposable sterile needle (G) and a $1 \mathrm{ml}$ disposable plastic syringe were used to withdraw blood from the caudal vein into heparinized saline $0.1 \mathrm{~g}$ heparin added to $10 \mathrm{ml}$ cold-blooded vertebrate Ringer's saline (CBVR) (Woo 1979). Blood samples were kept on ice until they were processed.

Determination of parasitaemia. The parasitemia was determined using a haemocytometer (Archer 1965). Briefly, blood from a fish infected with parasites was diluted (from 1:10 to 1:200) with ice-cold Ringer's saline in a white or a red blood cell dilution pipette (Fisher USA). The pipette was shaken for $30 \mathrm{~s}$ on a Yankee pipette shaker. The suspension was dispensed into a haemocytometer and the number of parasites counted under a compound microscope at $160 \times$ magnification.

The haematocrit centrifuge technique (Woo \& Wehnert 1983) was used when there was less than one Cryptobia salmositica per microscope field (Ocular $\times 10$ and Objective $\times 16$ ). A volume of $0.05 \mathrm{ml}$ fish blood was drawn into a heparinized microhaemotocrit capillary tube. The tube was sealed on one end with Critoseal and centrifuged in an ice-cold IEC MB centrifuge at $13000 \times g$ for $4 \mathrm{~min}$. The tube was placed on a glass slide with a small drop of immersion oil at the junction of packed white cells and plasma. Parasites at the buffy layer were detected under a compound microscope at $100 \times$ magnifications.

Determination of complement-fixing antibodies using in vitro lysis test (Li \& Woo 1995). Complementfixing antibody detection was performed in U-bottom 96-well microtitre plates (DiaMed Lab Supplies Inc., Canada). Dulbecco's Phosphate Buffered Saline (PBS) containing $\mathrm{Ca}^{++}$and $\mathrm{Mg}^{++}$ions ( $\mathrm{pH} 7.2$, GrBCO) was dispensed into each well of a microtitre plate, which was kept on ice. Fish antiserum was heat inactivated at

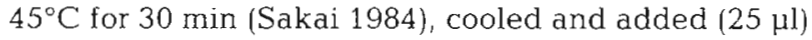
to the first well, and then diluted serially by 2 -fold dilution with PBS using a $25 \mu$ litertek diluter (Flow Laboratories, USA). Cryptobia salmositica from cultures (Woo \& Li 1990) were washed 3 times with ice-cold Ringer's saline. The parasites were resuspended and counted using a haemocytometer. The suspension was diluted with ice-cold Ringer's saline until $1 \mathrm{ml}$ contained approximately $4.0 \times 10^{3}$ parasites (approximately 100 parasites per $25 \mu \mathrm{l}$ ). A volume of $25 \mu \mathrm{l}$ freshly collected plasma from naive adult rainbow trout (as a source of complement) and $25 \mu$ of parasites suspension were added into each well containing the diluted antiserum. The plate was examined under an inverted microscope at $1.0 \times 10^{2}$ magnifications for living parasites $3 \mathrm{~h}$ after incubation at $10^{\circ} \mathrm{C}$. The titre of complement-fixing antibodies was the maximum antiserum dilution in which all parasites were lysed.

Production and isotyping of monoclonal antibody. Hybridomas were generated (Feng \& Woo 1996) by immunizing BALB/c mice (Charles River Canada Inc., St. Constant, Quebec) intraperitoneally with $1 \times 10^{7}$ washed live Cryptobia salmositica from cultures. The technique for producing hybridomas was as described by Oi \& Herzenberg (1980) with some modifications (Lam et al. 1987). Briefly, mouse spleen cells (5 wk after immunization) were fused with NS-1 myeloma cells in a 10:1 ratio using PEG fusogen $[40 \%$ polyethylene glycol (PEG; Sigma), $4 \%$ dimethyl sulfoxide (DMSO; Sigma) in Dulbecco's Modified Eagle Medium 
(D-MEM; Gibco]. The hybridomas were selected with HAT-medium and incubated at $37^{\circ} \mathrm{C}$ in a $5 \% \mathrm{CO}_{2}$ incubator, screened for production of antibodies against C. salmositica using ELISA (Feng \& Woo 1996) and positive hybridomas were then cloned by the limited dilution method (Lam et al. 1987) or using the 'single cell pick' method of Harlow \& Lane (1988). One positive hybridoma was selected; the monoclonal antibody it produced was designated MAb-001.

MAb-001 was isotyped using a ELISA-based Mouse Typer Isotyping Kit (Bio-Rad). Large volumes of MAb001 were produced for the in vivo study and this was done using the Cell-Pharm ${ }^{\mathrm{TM}}$ mini bioreactor system (Unisyn Technologies, Milford, MA 01757, USA). The harvested MAb-001 in D-MEM culture medium containing $10 \%$ fetal bovine serum was adjusted with CBVR to optical density value 0.49 using ELISA and about $0.2 \mathrm{ml}$ of this antibody was intraperitoneally (i.p.) injected into each fish.

Convalescent plasma preparation. Convalescent plasma was also used in the present study as a positive control. Fish that had recovered from a Cryptobia salmositica infection were challenged with $100000 \mathrm{C}$. salmositica. Two weeks after challenge, the fish were bled for convalescent plasma. The titre of the complement antibody in antisera was determined using the in vitro lysis test and was 1:64.

Sodium dodecyl sulphate-polyacrylamide gel electrophoresis (SDS-PAGE) of MAb-001. Monoclonal antibody (hybridoma supernatant, approximately $5 \mathrm{Hg}$ protein per sample well) was mixed with an equal volume of Laemmli buffer without mercaptoethanol (Laemmli 1970 ) and was electrophoresed at $20^{\circ} \mathrm{C}$ into $10 \%$ running gel at $100 \mathrm{~V}$ for $1.5 \mathrm{~h}$. Gels were stained with Coomassie brilliant blue or used for immunoblotting.

Western immunoblotting. After SDS-PAGE, the monoclonal antibody was transferred to nitrocellulose membrane (Towbin et al. 1979). Electrophoretic transfer was for $2 \mathrm{~h}$ at $100 \mathrm{~V}$. The membrane was blocked with a $5 \%$ solution of skim milk in Tris buffered saline (TBS, pH 7.5), washed in TBS, and incubated in 1:20 dilution of trout plasma (fish injected with either MAb-001 or CBVR) overnight at room temperature. A positive control of rabbit anti-mouse IgG [Sigma, diluted 1:3000 in 3\% skim milk/TBS with Tween 20 (TTBS)] was included. A nitrocellulose membrane incubated in naive fish plasma was used as a negative control. Membranes were washed in TTBS followed by TBS ( 2 washes each, 5 min per wash), and then incubated for $1 \mathrm{~h}$ in either goat antirabbit IgG or goat anti-trout immunoglobulin conjugated to alkaline phosphatase (Bio-Rad) diluted 1:3000 in 3\% skim milk/TTBS. After incubation the nitrocellulose was washed and incubated in the enzyme substrate, 5-bromo-4-chloro-3-indoly phosphate/Nitroblue tetrazolium (Bio-Rad) for $20 \mathrm{~min}$.
Experimental design. Therapeutic action of $M A b-$ 001 in fish with acute infections: Eighty rainbow trout were randomly divided into 4 groups $(1,2,3 \& 4, \mathrm{n}=$ 20 ) and each group was further divided into 2 subgroups ( $a$ and b). Fish in $1 \mathrm{a}, 2 \mathrm{a}, 3 \mathrm{a}$ and $4 \mathrm{a}$ were i.p. infected with 2000 (low dase) virulent Cryptobia salmositica, and fish in $1 \mathrm{~b}, 2 \mathrm{~b}, 3 \mathrm{~b}$ and $4 \mathrm{~b}$ were infected with 20000 (high dose) virulent C. salmositica (from an infected fish). Blood $(0.1 \mathrm{ml})$ was withdrawn weekly from the caudal vein of each fish using a needle and heparinized syringe and the parasitaemia was determined. Three weeks after infection, parasitaemias were high (about 1 to $5 \times 10^{6} \mathrm{ml}^{-1}$ blood) in all groups, and fish were ready for antibody treatment. Fish were bled to determine parasitaemias prior to i.p. antibody injection. Fish in group 1 were injected with MAb-001 ( $4 \%$ body weight in $\mathrm{ml}$ per fish) and fish in group 2 were injected with convalescent plasma; fish in group 3 were injected with CBVR, and fish in group 4 were injected twice with MAb-001, the 2 injections being $3 \mathrm{~d}$ apart. Fish in groups 1, 2 and 3 were bled at $48 \mathrm{~h}$ after injection and parasitaemias were determined. Groups $1,2,3$ and 4 were bled at 1 wk after injection further to determine their parasitaemias.

Prophylactic effects of $\mathbf{M A b - 0 0 1}$ : An additional 80 rainbow trout were randomly divided into 4 groups (I, II, III \& IV, $\mathrm{n}=20$ ). In the first week, fish in group I were injected with MAb-001 (the protein concentration was brought to $1 \mathrm{mg} \mathrm{ml}^{-1}$ in CBVR; $4 \%$ fish body weight in $\mathrm{ml}$ per fish) every day and fish in group II were injected with MAb-001 every other day. Fish in group III were injected with convalescent plasma every day. Fish in group IV were injected with CBVR every day. One day after the first injection, each group was sub-divided into 2 sub-groups ( $a$ and $b, n=10$ ). Fish in Ia, IIa, IIIa and IVa were i.p. infected with 2000 (low dose) virulent Cryptobia salmositica (from an infected fish), and fish in sub-groups Ib, IIb, IIIb and IVb were infected with 20000 (high dose) virulent C. salmositica.

Blood $(0.1 \mathrm{ml})$ was withdrawn weekly from the caudal vein of each fish using a needle and heparinized syringe and the parasitaemia was determined.

Effects of MAb-001 on the production of antibodies in fish: To determine the effects of heterogeneous monoclonal antibody on the endogenous protective immunity in fish, plasma from fish in group I (prophylactic, injected with monoclonal antibody on Day 0,1 , $2,3,4,5,6,7$ ), group 1 (therapeutic, 3 wk after MAb injection) and in group IV (fish injected with CBVR at same time as group I) were collected after infection and heated at $45^{\circ} \mathrm{C}$ for $30 \mathrm{~min}$ (Sakai 1984) to inactivate the endogenous complement. The plasma were then stored at $-20^{\circ} \mathrm{C}$ until used to detect complementfixing antibody (CFAb) against Cryptobia salmositica. 
Additionally, plasma from fish in group I ( 6 wk after MAb injection) and group 1 ( $3 \mathrm{wk}$ after $\mathrm{MAb}$ injection) were used to determine their humoral response against MAb-001 using immunoblot. Plasma from group IV was used as a negative controls.

Statistics: All data were analyzed using 1-way analysis of variance. Multiple comparisons among means were made using Duncan's Multiple-Range Test when the analysis of variance value was significant $(\mathrm{p}<0.05)$ (Steel \& Torri 1980).

\section{RESULTS}

\section{Therapeutic action of MAb-001 in fish with acute infections}

Forty-eight hours after injection of MAb-001, the parasitaemia in fish in group 1 (injected with MAb-001 at $3 \mathrm{wk}$ after infection) was significantly lowered ( $\mathrm{p}<$ 0.05). The same result was seen in group 2 (injected with convalescent plasma). However, there were no significant differences in parasitaemias in group 3 before and after injection of CBVR (Fig. 1). The parasitaemia in sub-group 1a (low-dose infection) was lower than that in sub-group $1 \mathrm{~b}$ (high-dose infection) before antibody injection. However, a higher percentage of parasites ( 60 to $75 \%$ ) in sub-group 1 b was eliminated than in sub-group 1a (53 to 68\%) after injection of MAb-001. However, the parasitaemias in sub-groups $2 b$ and $3 b$ were not different from subgroups $2 \mathrm{a}$ and $3 \mathrm{a}$.

One week after MAb-001 injection, the parasitaemias in group 1 and in group 2 were still significantly lower than that prior to MAb injection ( $p<0.05$ ). Although there was a slight drop in parasitaemia in group 3, there was no statistical difference between the parasitaemias prior to and after CBVR injection (Fig. 2).

After a double dose of MAb-001 injection, the parasitaemias in sub-groups $4 \mathrm{a}$ and $4 \mathrm{~b}$ were significantly lower (80 to $90 \%$ ) than that prior to MAb injection. They were also 10 to $20 \%$ lower than in sub-groups $1 \mathrm{a}$ and $1 \mathrm{~b}$ (injected with a single dose of MAb-001) at $1 \mathrm{wk}$ after MAb-001 injection. However, there was no statistical difference in parasitaemias between a single- and a double-dose injected fish at 1 wh after $\mathrm{MAb}$ injection (Fig. 3).

\section{Prophylactic effects of MAb-001}

Using the haematocrit centrifuge technique, 5/10 fish in sub-group Ia, 6/10 fish in sub-group Ib, 1/10 fish in sub-group Ila and $2 / 10$ fish in sub-group IIb had de-

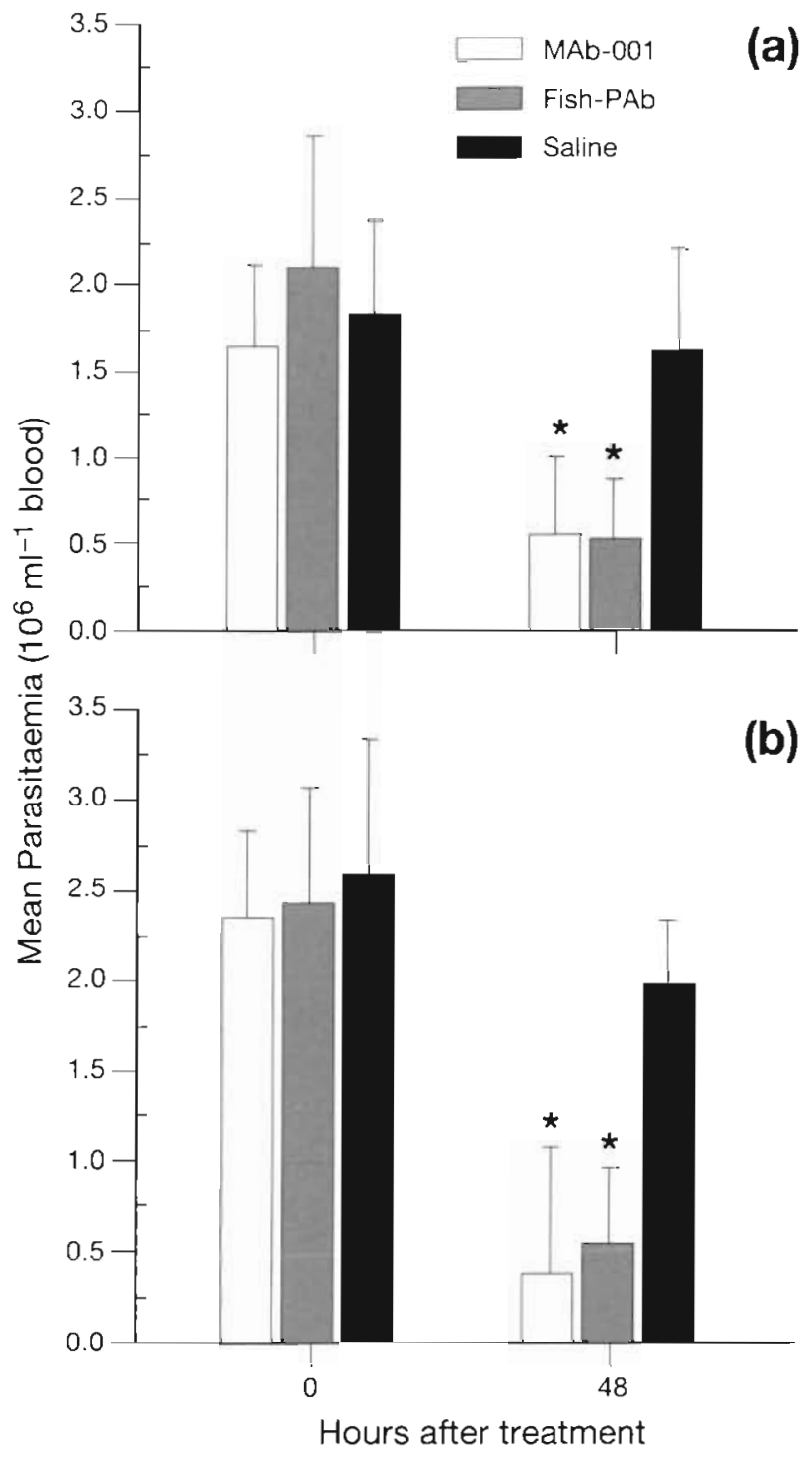

Fig. 1. Parasitaemias in fish $48 \mathrm{~h}$ after injection of antibodies. (a) Parasitaemias in fish injected with 2000 parasites per fish (low dose); (b) parasitaemias in fish injected with 20000 parasites per fish (high dose). MAb-001: MAb-injected fish; FishPAb: convalescent plasma-injected fish; Saline: cold-blooded vertebrate Ringer's saline-injected fish. "Significantly lower than that prior to MAb injection

tectable parasites at 1 wh after infection. No parasites were detected in fish in sub-group IIIa, and 1/10 fish in sub-group IIIb had detectable parasites. However, $7 / 10$ fish in sub-groups IVa and IVb had detectable parasites at 1 wk after infection.

Also, at 1 wk after infection the numbers of parasites in all groups infected with 2000 parasites were significantly $(p<0.05)$ lower than those in fish infected with 20000 parasites. However, the number of the parasites in fish in group II (which received a MAb-001 injection 


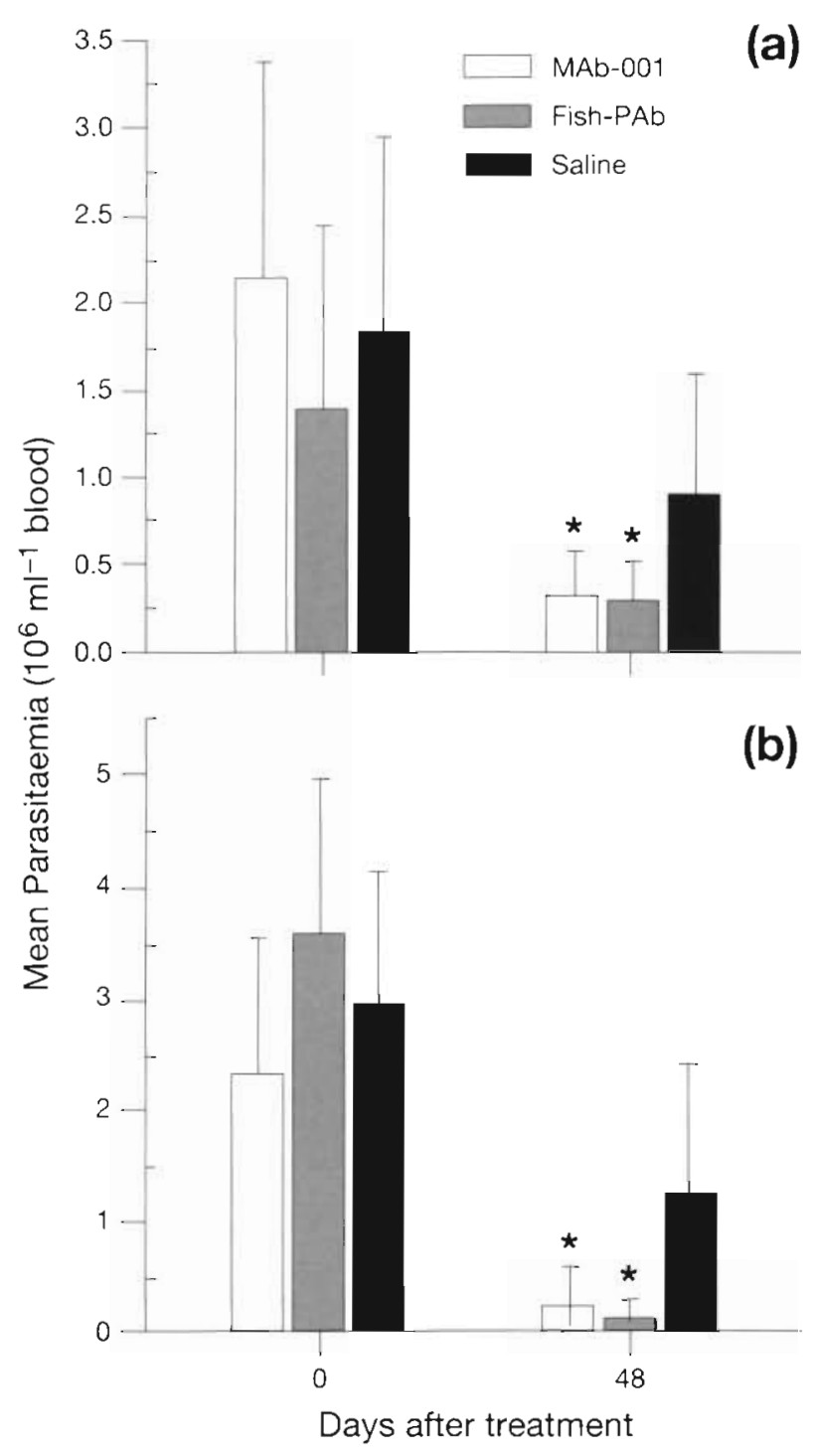

Fig. 2. Parasitaemias in fish $1 \mathrm{wk}$ after injection of antibodies. (a) Parasitaemias in fish injected with 2000 parasites per fish (low dose); (b) parasitaemias in fish injected with 20000 parasites per fish (high dose). MAb-001: MAb-injected fish; FishPAb: convalescent plasma-injected fish; Saline: cold-blooded vertebrate Ringer's saline-injected fish. *Significantly lower than that prior MAb injection

every other day in the first week) was lower, but not to the extent of being statistically significant, than that in fish in group IV (which received a CBVR injection every day in the first week), although the number of parasites in fish in group I (which received a MAb-001 injection every day in the first week) was not significantly different from that in fish in group IV (Table 1).

Parasitaemias in all groups peaked at 3 wk after infection. Fish in sub-groups Ia and Ib (injected with MAb every day during the first week of infection) had significantly higher parasitaemias than those in sub-

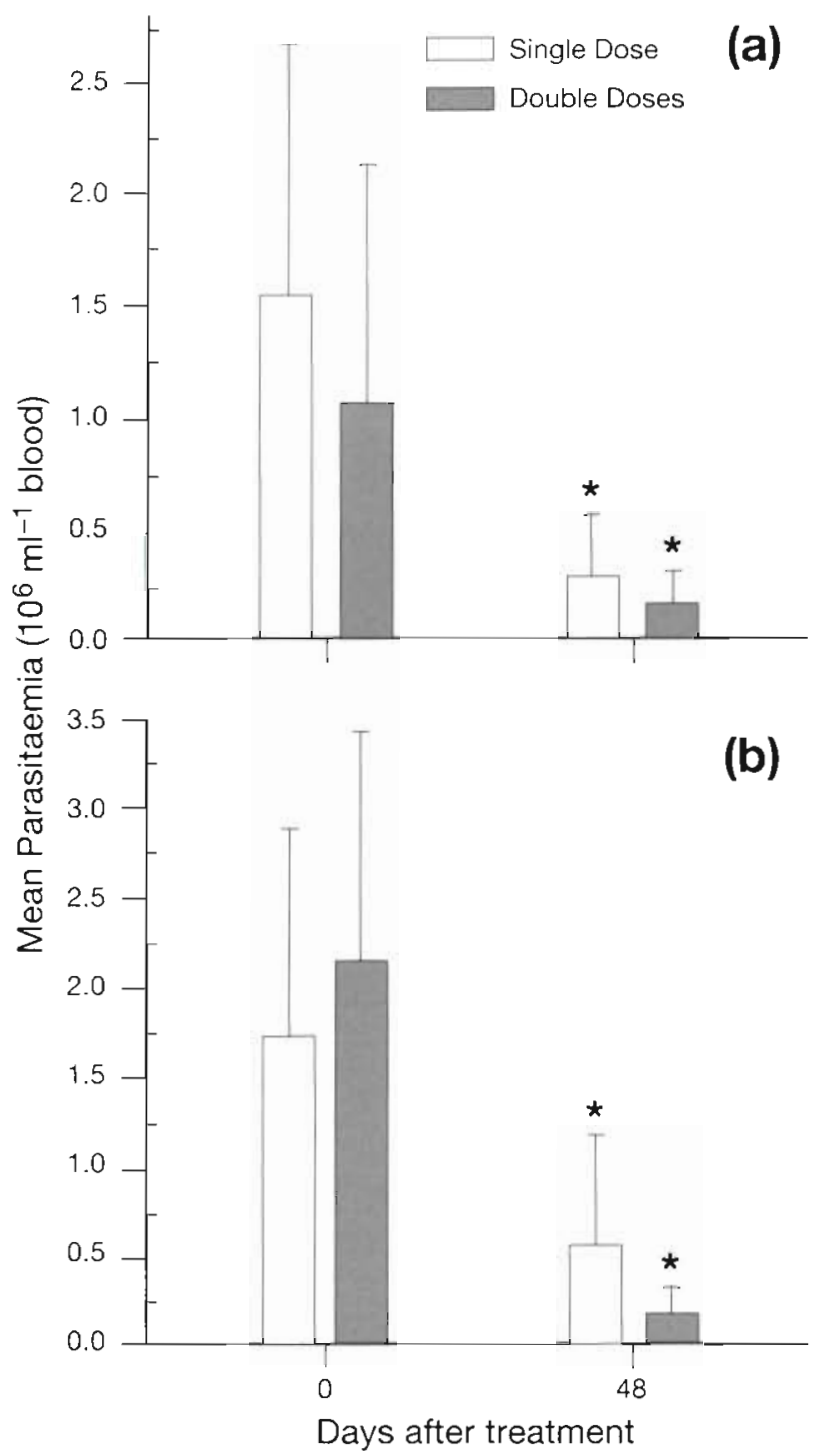

Fig. 3. Parasitaemias in fish 1 wk after a single dose or a double dose of MAb-001 injection. (a) Parasitaemias in fish injected with 2000 parasites per fish (low dose); (b) parasitaemias in fish injected with 20000 parasites per fish (high dose). Single: dose fish with single-dose MAb injection; double dose: fish with double-dose MAb injection. *Significantly lower than that prior MAb injection

groups IIIa and IIIb (injected with convalescent fish plasma, positive control), and in sub-groups IVa and IVb (injected with CBVR, negative control) (Fig. 4). However, parasitaemias in sub-groups IIa and IIb (injected with MAb every other day during the first week of infection) were lower than in fish in sub-groups IVa and IVb (injected with CBVR negative control) and were similar to those in fish in sub-groups IIIa and IIIb (injected with convalescent plasma) although there were no significant differences in parasitaemias between fish in groups II, III and IV (Fig. 5). 
Table 1. Parasitaemias in fish injected with MAb-001 at 1 wk after Cryptobia salmositica infection. MAb-a: fish were injected with MAb-001 every day after infection; MAb-b: fish were injected with MAb-001 every other day after infection; PAb: fish anti-C salmositica polyclonal antibody injection (every day)i CBVR: cold-blood vertebrate Ringer's saline injection (every day)

\begin{tabular}{|c|c|c|c|}
\hline $\begin{array}{l}\text { Inoculation } \\
\text { dose }\end{array}$ & Treatment & $\begin{array}{l}\text { No. fish with infection/ } \\
\text { No. infected fish injected } \\
\text { with MAb-001 }\end{array}$ & $\begin{array}{l}\text { No. parasites per } \\
\text { haematocrit } \\
\text { tube of blood }\end{array}$ \\
\hline $\begin{array}{r}2000 \\
20000\end{array}$ & MAb-a & $\begin{array}{l}5 / 10 \\
6 / 10\end{array}$ & $\begin{array}{r}2 \\
21\end{array}$ \\
\hline $\begin{array}{r}2000 \\
20000\end{array}$ & $M A b-b$ & $\begin{array}{l}1 / 10^{\circ} \\
2 / 10^{\circ}\end{array}$ & $1^{\circ}$. \\
\hline $\begin{array}{r}2000 \\
20000\end{array}$ & PAb & $\begin{array}{l}0 / 10^{\circ} \\
1 / 10^{\circ}\end{array}$ & $\begin{array}{l}0^{\circ} \\
1^{\circ}\end{array}$ \\
\hline $\begin{array}{r}2000 \\
20000\end{array}$ & CBVR & $\begin{array}{l}6 / 10 \\
7 / 10\end{array}$ & $\begin{array}{r}5 \\
20\end{array}$ \\
\hline
\end{tabular}

can be attributed neither to nonspecific factors in the hybridoma culture medium, since the hybridoma culture medium had no effects on Cryptobia salmositica (Feng \& Woo 1996), nor to the recipient's immune system, because control fish (injected with saline) had high parasitaemias at $48 \mathrm{~h}$ after injection of saline. Even at 1 wk after treatment, the parasitaemias in all groups of antibody-injected fish were still low. Although there was no statistical difference in parasitaemia before and after CBVR injection in the CBVRinjected fish, the numbers of parasites in MAb-injected fish and convalescent plasma-injected fish were statistically lower than in CBVR-injected fish.

\section{Detection of antibodies in MAb injected infected fish}

$$
\begin{gathered}
\text { Complement-Fixing Antibody (CFAb) against } \\
\text { Cryptobia salmositica }
\end{gathered}
$$

Complement-fixing antibodies were detected in both experimental (injected with MAb-001, group I) and control fish (injected with CBVR, group IV) at $5 \mathrm{wk}$ after infection. However, 10/10 CBVR-injected fish had detectable complement-fixing antibodies, while only $3 / 10 \mathrm{MAb}$-injected fish had detectable complement-fixing antibodies.

\section{Antibodies against MAb-001}

Antibodies against MAb-001 were detected in MAbinjected infected fish (group I) using both dot blot and Western immunoblotting. When MAb-001 was transferred from gel to nitrocellulose after SDS-PAGE, it was detected as an intensive band (molecular weight about $150 \mathrm{kDa}$ ) by fish antibodies (group I, prophylactic). The intensity of the band in the positive control was lighter than that of fish injected with MAb-001 every day, and a very weak reaction was detected in group 1 (therapeutic). However, no reactions were seen in fish injected with CBVR and the negative control (Fig. 6).

\section{DISCUSSION}

Parasitaemias in fish were significantly reduced $48 \mathrm{~h}$ after injection of MAb-001; this indicates that MAb001 is curative during the acute phase of the disease. The reduction in parasitaemias in MAb-injected fish

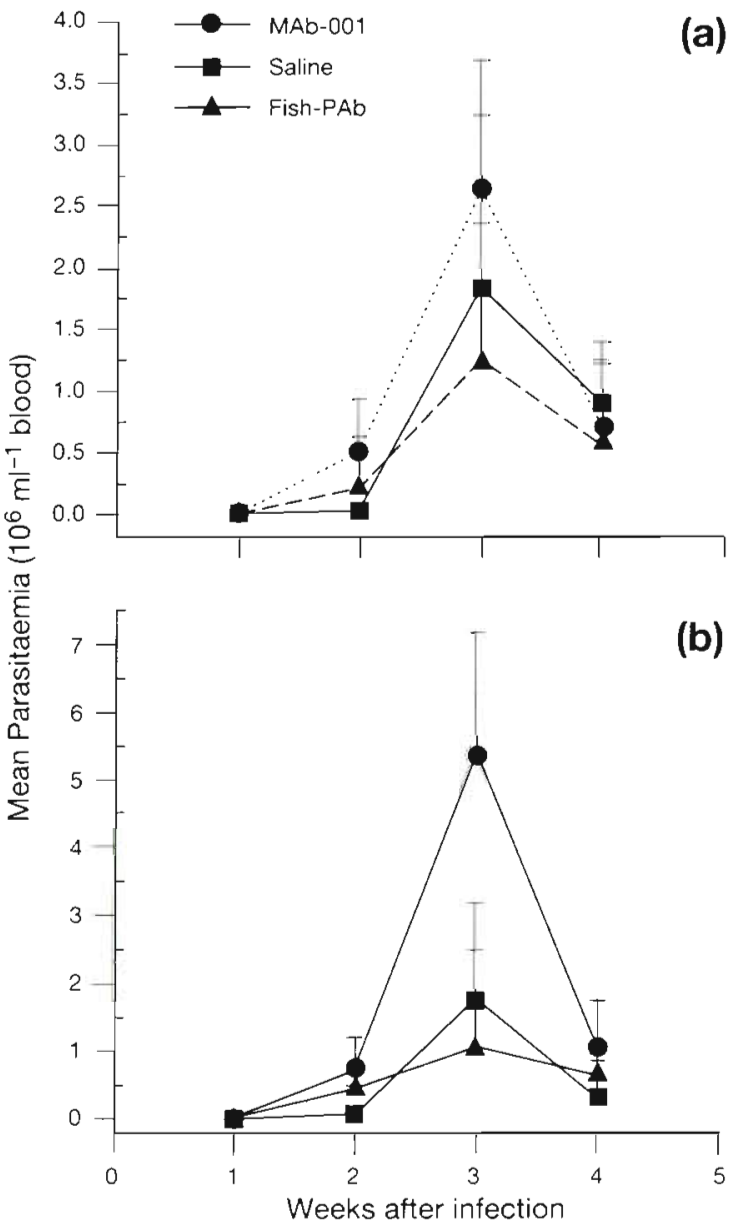

Fig. 4. Parasitaemias in fish injected with MAb-001 every day in the first week. (a) Parasitaemias in fish injected with 2000 parasites per fish (low dose); (b) parasitaemias in fish injected with 20000 parasites per fish (high dose). MAb-001: MAb-injected fish; Fish-PAb: convalescent plasma-injected tish; Saline: fish injected with cold-blooded vertebrate Ringer's saline 


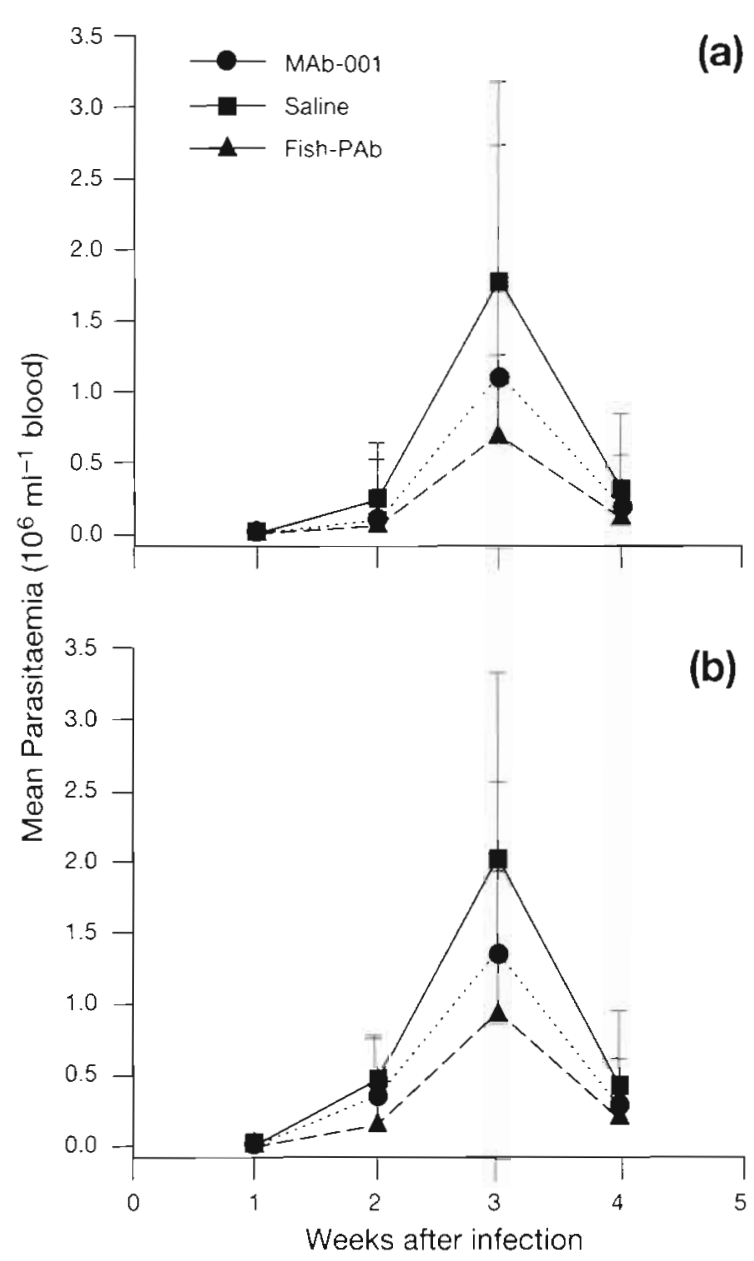

Fig. 5. Parasitaemias in fish injected with MAb-001 every other day in the first week. (a) Parasitaemias in fish injected with 2000 parasites per fish (low dose); (b) parasitaemias in fish injected with 20000 parasites per fish (high dose). MAb-001. MAbinjected fish; Fish-PAb: convalescent plasma-injected fish; Saline: fish injected with cold-blooded vertebrate Ringer's saline

These indicates that the transferred antibodies eliminated parasites in MAb-injected and convalescent plasma-injected fish.

There was no significant difference in parasitaemias between fish injected with a single or a double dose of MAb-001 at 1 wk after injection. This might be because the parasitaemias were low (at $48 \mathrm{~h}$ after MAb injection, parasitaemias were 3 times lower than before injection). This low parasitaemia reduced the chance of MAb-001 coming into contact with parasites before the antibody was inactivated by the fish because MAb-001 was of mouse origin. The antibody eliminated a higher percentage of parasites in fish with higher parasitaemias since the chance of contact between parasites and MAb-001 was greater.

Antibodies of the IgG 1 subclass are generally not efficient in activating complement and this is the case

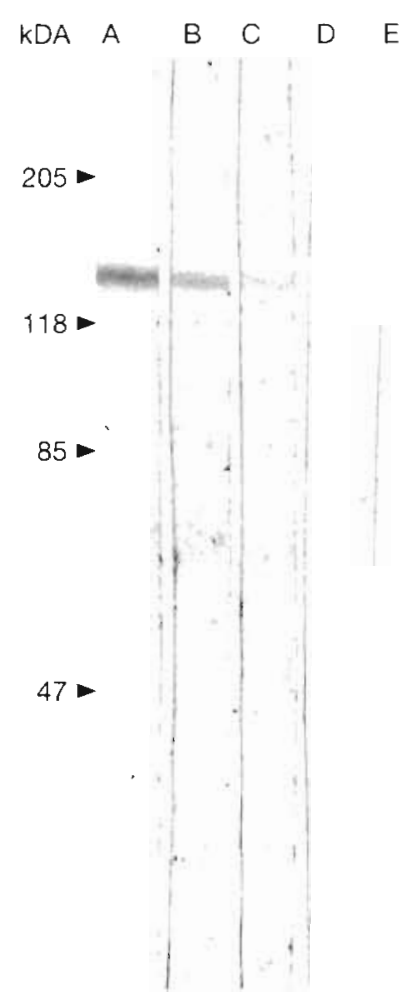

Fig. 6. Detection of antibodies against MAb-001 in plasma from MAb-injected fish with immunoblot. Lane a: antibodies against MAb-001 were detected as an intensive band at $150 \mathrm{kDa}$ when MAb-001 on the nitrocellulose strip was incubated with plasma from MAb-injected fish (group I, prophylactic); lane b: MAb-001 on the nitrocellulose was directly incubated with goat anti-mouse immunoglobulin; lane c: antibodies against MAb-001 were detected as an faint band in MAb-injected fish (group 1, therapeutic); lane d, e: no reaction was shown on the nitrocellulose strand after being incubated with plasma from saline-injected fish and naive fish. Number on the left is the pre-stained protein standard (Bio-Rad)

with MAb-001. In an earlier study (Feng \& Woo 1996), we showed that they do not activate complement to lyse the parasite and mediate parasite cytotoxity via another mechanism. Alves et al. (1983) also reported a monoclonal antibody with complement-independent cytotoxity that decreased the incorporation of radiolabelled uridine and thymidine, and caused immobility and death in Trypanosoma cruzi. We (Feng \& Woo 1996) suggested that MAb-001 mediates Cryptobia salmositica cytotoxity by affecting its metabolic process because parasites exposed to the antibody under in vitro conditions did not multiply and were dead in 2 to 3 wk. Since MAb-001 recognizes a glycoprotein on the surface membrane of $C$. salmositica, we assume that it may act on the parasite as a toxic lectin. Lectins bind to carbohydrate receptors on the cell membrane and inhibit membrane transport of nutrients or they enter the cytoplasm and inactivate protein synthesis. 
Freeman et al. (1980) reported 2 murine monoclonal antibodies (against merozoites of Plasmodium yoelin) which prevented the development of infection or eliminated an established infection with continuous administration of antibody to mice. Butscher \& Faubert (1988) showed that mice injected with a murine monoclonal antibody (every other day before and after infection) had nearly 3 times fewer trophozoites than did mice treated with negative ascites. Our monoclonal antibody did not prevent disease nor eliminated the parasite in our prophylactic study because we infected our fish with a low number of parasites, our monoclonal antibody was of mouse origin, and we stopped injecting our fish with MAb-001 a week after infection, when parasitaemias were still low. As pointed out earlier (in our therapeutic study), the antibody is effective when the parasitaemia is high; the chance of the antibody coming into contact with parasites in fish with a low parasitaemia was reduced, and in our prophylactic study in which the number of parasites was high (e.g. 3 to $4 \mathrm{wk}$ after infection), most if not all the murine antibody would be degraded by the fish immune system. We detected antibodies against MAb-001 in our antibody-injected fish (5 wk after injection). However, Freeman et al. (1980) and Butcher \& Faubert (1988) injected murine monoclonal antibodies into mice and they were successful because the monoclonal antibodies functioned as mouse immunoglobulins. Also, in our prophylactic study, fish injected with MAb-001 had significantly higher parasitaemias than fish injected with saline or convalescent plasma. One of the obvious reasons for the higher parasitaemias in MAb-001injected fish is antigenic competition between our murine monoclonal antibody and the parasite antigen -7 of $10 \mathrm{MAb}-001$-injected fish had no detectable complement-fixing antibodies against Cryptobia salmositica while 10 of 10 fish (injected with saline) had antibodies which lysed parasites under in vitro conditions. Though murine monoclonal antibodies against Ichthyophthirius multifiliis provided complete protection against infection in channel catfish, the mechanism of protection is believed to be different; the antibody when attached to the parasites forces the parasite to leave the host (Clark et al. 1996).

Our conclusion is that MAb-001 is therapeutic and that it significantly lowered the parasitaemia when injected into infected fish during the acute phase; however, the protection was only partial. Similarly, plasma from recovered and challenged fish did not eliminate all of the parasite in infected fish either. This could be because there were insufficient antibodies (in both the MAb-inoculum and in the convalescent plasma) to lyse all parasites or because both humoral and cellmediated immunity are necessary for complete protection.
Acknowledgements. This study was supported by grants from the Department of Fisheries \& Oceans and the Natural Science and Engineering Research Council of Canada to P.T.K.W.

\section{LITERATURE CITED}

Alves MJM, Aikawa M, Nussenzweig RS (1983) Monoclonal antibodies to Trypanosoma cruzi inhibit motility and nucleic acid synthesis of culture forms. Infect Immun 39: $377-382$

Araguth MF, Rodrigues MM, Yoshida N (1988) Trypanosoma cruzi metacylic trypomastigotes neutralization by the stage-specific monoclonal antibody $1 \mathrm{G} 7$ and immunogenicity of $90 \mathrm{kD}$ surface antigen. Parasite Immunol 10: $707-713$

Archer RK (1965) Haematological techniques for use on animals. Blackwell Scientific Publications, Oxford

Boyle DB, Newbold CI, Smith CC, Brown KN (1982) Monoclonal antibodies that protect in vivo against Plasmodium chabaudi recognize a $250,000-D a l t o n$ parasite polypeptide. Infect Immun 38:94-102

Butscher WG, Faubert GM (1988) The therapeutic action of monoclonal antibodies against a surface glycoprotein of Giardia muris. Immunology 64:175-180

Campbell JD, Faubert GM (1994) Recognition of Giardia lamblia cyst-specific antigens by monoclonal antibodies. Parasite Immunol 16:211-219

Clark TG, Lin TL, Dickerson HW (1996) Surface antigen cross-linking triggers forced exit of a protozoan parasite from its host. Proc Natl Acad Sci USA 93:6825-6829

Epstein N, Miller LH, Kaushel DC, Udeinya IJ, Renes J, Howard RJ, Asofsky R, Aikawa M, Hess RL (1981) Monoclonal antibodies against a specific surface determinant on malaria (Plasmodium knowlesi) merozoites block erythrocyte invasion. J Immunol 127:212-217

Feng S, Woo PTK (1996) Biological characterization of a monoclonal antibody against piscine haemoflagellate Cryptobia salmositica Katz 1951. J Fish Dis 19:137-143

Freeman RR, Trejdosiewicz AJ, Cross GAM (1980) Protective monoclonal antibodies recognizing stage-specific merozoite antigens of a rodent malaria parasite. Nature 284 $366-368$

Harlow E, Lane D (1988) Antibodies-a laboratory manual. Cold Spring Harbor Laboratory Press, New York, p 283-318

Jones SRM, Woo PTK (1987) The immune response of rainbow trout, Salmo gairdneri Richardson, to the haemoflagellate Cryptobia salmositica Katz, 1951. J Fish Dis 10: 395-402

Laemmli UK (1970) Cleavage of structure proteins during the assembly of the head of bacteriophage T4. Nature 227 : $680-685$

Lam JS, Mcdonald LA, Lam MYC, Duchsene LGM, Southam GG (1987) Production and characterization of monoclonal antibodies against serotype strains of Pseudomonas aeruginosa. Infect Immun 55:1051-1057

Li S. Woo PTK (1995) Efficacy of a Iive Cryptobia salmositica vaccine, and the mechanism of protection in vaccinated Oncorhynchus mykiss (Walbaum) against cryptobiosis. Vet Immunol Immunopathol 48:343-353

Lin TL, Clark TG, Dickerson HW (1994) Passive immunization of channel catfish against Ichthyophthirius multifilits using immobilizing murine monoclonal antibodies. 72nd Conference of Research Workers in Animal Diseases, Chicago (Abstract) 
McNicol RE, Noakes DL (1979) Caudal fin branding fish for individual recognition in behaviour studies. Behav Res Methods Instrum 11:95-97

Nash TE, Aggarwal A (1986) Cytotoxicity of monoclonal antibodies to a subset of Giardia isolates. J Immunol 136: $2628-2632$

Oi V, Herzenberg LA (1980) Immunoglobulin-producing hybrid cell lines. In: Misher BB, Shiigi SM (eds) Selected methods in cellular immunology. WH Freeman, San Francisco, p 351-372

Pinder M, Melick AV, Vernet G (1987) Analysis of protective epitope on the variant surface glycoprotein of a Trypanosoma brucei brucei (DiTat 1.3) using monoclonal antibodies. Parasite Immunol 9:395-400

Sakai DK (1984) Opsonization by fish antibody and complement in the immune phagocytosis by peritoneal exudate cells isolated from salmonid fishes. J Fish Dis 7:29-38

Saul A, Myler P, Schofield L, Kidson C (1984) A high molecular weight antigen in Plasmodium falciparum recognized by inhibitory monoclonal antibodies. Parasite Immunol 6: $39-50$

Sitja-Bobadilla A, Woo PTK (1994) An enzyme-linked immunosorbent assay (ELISA) for the detection of antibodies against the pathogenic haemoflagellate, Cryptobia salmositica Katz, and protection against cryptobiosis in juvenile rainbow trout, Oncorhynchus mykiss (Walbaum). inoculated with a live vaccine. J Fish Dis 17:399-408

Steel RGD, Torri JH (1980) A biometrical approach. Principles and procedures of statistics, 2nd edn. McGraw-Hill Book

Responsible Subject Editor: W. Körting, Hannover, Germany
Company, New York

Thomas PT, Woo PTK (1990) In vivo and in vitro cell-mediated immune response of rainbow trout, Oncorhynchus mykiss (Walbaum), against Cryptobia salmositica Katz, 1951 (Sarcomastigophora: Kinetoplastida). J Fish Dis 13:423-433

Thomas PT, Woo PTK (1992) Anorexia in rainbow trout, Oncorhynchus mykiss (Walbaum), infected with Cryptobia salmositica (Sarcomastigophora: Kinetoplastida): its onset and contribution to the immunodepression. J Fish Dis 15: $443-447$

Towbin M, Staehlin T, Gorden J (1979) Electrophoretic transfer of proteins from polyacrylamide gels to nitrocellulose sheets: procedure and some application. Proc Natl Acad Sci USA $76: 4350-4354$

Woo PTK (1979) Trypanoplasma salmositica: experimental infections in rainbow trout, Salmo gairdneri. Exp Parasitol $47: 36-48$

Woo PTK (1987) Cryptobia and cryptobiosis in fishes. Adv Parasitol 26:199-237

Woo PTK (1994) Flagellate parasites of fish. In: J Kreier (ed) Parasitic Protozoa, 2nd edn, Vol 8. Academic Press, New York, p 1-80

Woo PTK, Li S (1990) In vitro attenuation of Cryptobia salmositica and its use as a live vaccine against cryptobiosis in Oncorhynchus mykiss. J Parasitol 76:752-755

Woo PTK, Wehnert SD (1983) Direct transmission of a haemoflagellate, Cryptobia salmositica (Kinetoplastida: Bodonina) between rainbow trout under laboratory conditions. J Protozool 30:334-337

Manuscript first received: June 6, 1996

Revised version accepted: October 10,1996 